\title{
Adapting a Standardized, Industry-Proven Tool to Measure Patients' Perceptions of Quality at the Point of Care in a PET/CT Center
}

\author{
Farouk Dako ${ }^{1}$, Rick Wray ${ }^{2}$, Omer Awan ${ }^{1}$, and Rathan M. Subramaniam ${ }^{3}$ \\ ${ }^{1}$ Department of Radiology, Temple University Hospital, Philadelphia, Pennsylvania; ${ }^{2}$ Russell H. Morgan Department of Radiology \\ and Radiological Sciences, Johns Hopkins University, Baltimore, Maryland; and ${ }^{3}$ Department of Radiology and Advanced Imaging \\ Research Center, University of Texas Southwestern Medical Center, Dallas, Texas
}

\begin{abstract}
Patient satisfaction with health-care delivery is essential today. Using a psychometrically validated questionnaire-SERVPERFwe quantitatively measured patients' perceptions of the quality of service at the point of care in a PET/CT center, and we used this information to guide subsequent quality improvement interventions. SERVPERF is a survey instrument that measures performance for various services. It has demonstrated reliability and validity across various industries. The standard for measuring patient perception of quality in hospitals-the "Hospital Consumer Assessment of Health Care Providers and Systems" survey-does not include questions about the care received in a typical radiology department and is not performed at the point of care. Methods: 429 patients undergoing PET/CT examinations filled out an anonymous modified SERVPERF questionnaire on completion of imaging and reported their level of agreement with each of the 27 items by circling a Likert-type scale from 1 to 7 . Each item was designed to elicit a response on the patient's perception of performance on a metric of quality. Data were summarized as the mean of each item. The frequency of low scores $(\leq 3)$ was also calculated. Results: The items with the lowest mean score were "The department's physical facilities are visually appealing" (6.158) and "Documentation such as sign-in sheet, handouts, and brochures are visually appealing" (6.162). The item with the highest frequency of low scores $(\leq 3)$ was, "The department provides services at the promised time" (11/429 responses). Conclusion: Our study showed that patient perception of quality in a diagnostic radiology department can be measured with a standardized survey at the point of care delivery and used to direct patient-centered quality improvement interventions.
\end{abstract}

Key Words: PET/CT; patient perception of quality; patientcentered; quality assurance; SERVPERF

J Nucl Med Technol 2017; 45:285-289

DOI: 10.2967/jnmt.117.196170

\footnotetext{
Received Jun. 1, 2017; revision accepted Aug. 10, 2017.

For correspondence or reprints contact: Farouk Dako, Department of Radiology, Temple University Hospital, 3401 N. Broad St., Philadelphia, PA 19140.

E-mail: fdako123@gmail.com

Published online Oct. 17, 2017.

COPYRIGHT (c) 2017 by the Society of Nuclear Medicine and Molecular Imaging.
}

D espite technologic advancements in health care, the quality of care provided by our current health-care systems continues to be less than optimal $(1,2)$. A fundamental challenge in assessing quality revolves around the subjective nature of the definition of quality. From which perspective is it defined, and to whom does it apply? Various definitions have been offered from multiple organizations. The U.S. Agency for Health Care Research and Quality defines quality as "doing the right thing, at the right time, in the right way, for the right person and having the best possible result." (3). The Institute of Medicine states that quality is "the degree to which health services for individuals and populations increase the likelihood of desired health outcomes and are consistent with current professional knowledge." (1). Although these definitions capture the essence of quality in an ethereal manner, they are from the perspective of the system and are not necessarily patient-centric.

With the more recent focus on patient-centered care, the idea of quality is increasingly being shifted to the perspective of the patient. Traditionally in health-care delivery, measures of quality were limited to clinical outcomes. Patients' perceptions of quality are not limited to clinical outcomes and are decided on the basis of a holistic experience throughout the continuum of care (4). This is reflected in a more recent definition of quality, by Davis et al., as "providing the care that the patient needs, in the manner the patient desires, at the time the patient desires" (5).

The need to focus on the patients' whole experience is especially important in diagnostic radiology. When a patient goes to a diagnostic center for imaging, there are few clinical outcomes to use as the basis for perception of quality or satisfaction with care. In this situation, it behooves the radiologist to establish a systematic approach toward finding measurable data points that reflect patient experience and, in turn, satisfaction. In the words of Peter Drucker, with respect to quality, "if you can't measure it, you can't manage it" (6).

Measurement of quality is essential because it helps to identify areas for improvement as well as monitoring the 
effectiveness and unintended results of quality improvement interventions $(2,7)$. With the advances in the validity and reliability of tools to measure quality, it is imperative that quality improvement initiatives be guided by patient feedback and aimed at improving a patient's overall experience (8). Industries outside the health-care realm are using standardized surveys, such as SERVPERF, to measure customer perceptions of quality in an effort to guide quality improvement interventions (8-12). These types of surveys can also be used in the health-care arena to gauge patient perceptions of quality. The purpose of this study was to quantitatively measure patients' perceptions of quality and satisfaction at the point of care in a diagnostic radiology center using a psychometrically validated questionnaire, SERVPERF, to guide subsequent quality improvement interventions.

\section{MATERIALS AND METHODS}

\section{Patient Selection}

The institutional review board approved this study, and all subjects gave written informed consent. Patients who underwent PET/CT at a tertiary institution from December 2014 through March 2015 were handed an anonymous survey on completion of imaging. The study was limited to outpatients for logistic reasons, including the fact that inpatients usually do not experience the full administrative spectrum of radiology departments, such as registration and wait time.

\section{SERVPERF}

SERVPERF is a survey instrument created by Cronin and Taylor in 1992 that captures quality by measuring performance for various services (9). This instrument, as a multidimensional or unidimensional scale, has demonstrated high reliability and validity worldwide across various industries, including health care, banking, transportation, telecommunications, and higher education, with a Cronbach $\alpha$, the estimate of the reliability of a psychometric test, ranging from 0.88 to 0.96 (9-13). Our questionnaire adapted the SERVPERF questionnaire, which contains 22 questions designed to elicit a response regarding patients' perceptions of performance on a metric of quality. We added 5 more questions, for a total of 27 (Table 1). Patients reported varying levels of agreement or disagreement with each item by circling 1-7 on a Likert-type scale, with 7 being the highest level of agreement and 1 the lowest. Our questionnaire included some nonidentifiable demographic information and the number of prior visits to the PET/CT center in the last year (0-3). Each of the 27 items was calculated individually, with no summative score given.

\section{Data Collection and Analysis}

After receiving their imaging service, patients were returned to the waiting room by a radiology technologist, who then handed them the 1-page paper-based survey to fill out. Patients completed

TABLE 1

Questions Measuring Perception of Quality and Satisfaction

\begin{tabular}{|c|c|}
\hline Question no. & Question \\
\hline 1 & The department's equipment is modern-looking \\
\hline 2 & The department's physical facilities are visually appealing \\
\hline 3 & The employees are neat and professionally appearing \\
\hline 4 & Documentation such as sign in sheet, handouts, and brochures are visually appealing \\
\hline 5 & The department has convenient hours of operation \\
\hline 6 & The department provides services as promised \\
\hline 7 & The department is dependable in handling patient service problems \\
\hline 8 & The employees provide services right the first time \\
\hline 9 & The department provides services at the promised time \\
\hline 10 & The employees insist on error-free documentation \\
\hline 11 & Employees keep users informed about when services will be performed \\
\hline 12 & Employees provide prompt service to patients \\
\hline 13 & Employees are always willing to help patients \\
\hline 14 & Employees are never too busy to respond to patients' requests \\
\hline 15 & Employees are courteous \\
\hline 16 & Employees instill confidence in patients \\
\hline 17 & Employees make patients feel safe while they receive services \\
\hline 18 & Employees have the knowledge to answer patient's questions \\
\hline 19 & Employees give patients individual attention \\
\hline 20 & Employees have patient's best interest at heart \\
\hline 21 & Employees deal with patients in a caring fashion \\
\hline 22 & Employees understand the specific needs of patients \\
\hline 23 & The quality of the PET/CT center services \\
\hline 24 & My satisfaction with the front desk service can be best described as: \\
\hline 25 & My satisfaction with the technologists' service can be best described as: \\
\hline 26 & My satisfaction with the doctors' service can be best described as: \\
\hline 27 & In summary, my satisfaction with the entire PET/CT center can best be described as: \\
\hline
\end{tabular}

Questions 1-22 are adapted from SERVPERF questionnaire and measure perception of quality. Responses are based on Likert-type scale (1-7) demonstrating varying levels of agreement or disagreement with each question. Questions 23-27 are additional questions to measure patient satisfaction. Responses are based on Likert-type scale (1-7) ranging from very poor to excellent. 
the surveys and dropped them into a locked box in the waiting room. The box was emptied at the end of each day by a member of the study team. Each questionnaire was numbered and printed by 1 of the 3 members of the primary study team, in order to track response rates and create a system of accountability among technologists handing them out.

The primary outcome was determining the mean score for each of the 27 questions and identifying the responses with the lowest scores. The questions with the highest frequency of low scores were also determined. A low score was defined as 3 or less. Data were then analyzed to assess patients' perceptions of quality and satisfaction stratified by number of visits (first visit vs. multiple visits in the past year), sex, and age (treated as a binary predictor variable $[<50$ y old or $\geq 50$ y old]) using 2 -sample $t$ tests. All statistical analyses were performed using Stata 13 (StataCorp).

\section{RESULTS}

\section{Framework}

Of the patients who visited the PET center during the specified time frame, $429(65 \%)$ completed the survey (age range, $15-86$ y; mean, 56 y; $54 \%$ female; $24 \%$ visiting the center for the first time).

\section{Findings}

The items with the lowest mean score were question 4 , "Documentation such as sign-in sheet, handouts, and brochure are visually appealing" (mean, 6.162) and question 2, "The department's physical facilities are visually appealing" (mean, 6.158). Patient satisfaction with the front desk staff (mean, 6.579) was lower than patient satisfaction with technologists and physicians. The item with the highest frequency of lower scores $(\leq 3)$ was question 9 , "The department provides services at the promised time" (11/429 responses). Table 2 shows results by item. There was no statistical difference in patients' perceptions of quality and satisfaction between first-time visits and multiple prior visits in the past year for any items in the survey, as shown in Table 3. There was also no difference in patients' perceptions of quality and satisfaction between men and women for any items in the survey, as seen in Table 3. Perception of quality was lower for patients younger than $50 \mathrm{y}$ than for those $50 \mathrm{y}$ or older for "the department's physical facilities are visually appealing" and satisfaction with the front desk service, at $P<0.030$ and $P<0.006$, respectively, as seen in Table 3.

\section{Intervention}

After 3 mo of data collection and analysis, relevant findings were discussed by a multidisciplinary team consisting of representatives from the front desk, management, radiology technologists, and the study team. On the basis of this discussion and patient feedback to the front-line staff, one of the questions with the lowest mean, "Documentation such as sign-in sheet, handouts, and brochures are visually appealing," and the question with the highest frequency of low scores $(\leq 3)$, "The department provides services at the promised time," were designated as issues requiring quality improvement intervention. Further analysis by all disciplines
TABLE 2

Mean Response for Each Item

\begin{tabular}{ll}
\hline Question no. & Mean \\
\hline 1 & $6.4113^{\star}$ \\
\hline 2 & $6.1580^{\star}$ \\
\hline 3 & 6.7400 \\
\hline 4 & $6.1620^{\star}$ \\
5 & $6.5600^{\star}$ \\
6 & 6.7429 \\
7 & 6.6554 \\
\hline 8 & 6.7264 \\
9 & $6.5915^{\dagger}$ \\
\hline 10 & $6.5898^{\star}$ \\
\hline 11 & 6.7275 \\
\hline 12 & 6.6784 \\
\hline 13 & 6.8061 \\
\hline 14 & 6.7629 \\
\hline 15 & 6.8235 \\
16 & 6.7676 \\
\hline 17 & 6.8014 \\
\hline 18 & 6.7765 \\
\hline 19 & 6.8099 \\
\hline 21 & 6.7962 \\
\hline 22 & 6.8075 \\
\hline 23 & 6.7536 \\
\hline 24 & 6.7392 \\
\hline 26 & $6.5792^{\star}$ \\
\hline 27 & 6.8467 \\
\hline & 6.7660 \\
\hline
\end{tabular}

*Scores lower than mean.

${ }^{\dagger}$ Item with highest frequency of low scores $(\leq 3)$.

established that changes in protocol were needed to effect this change in quality. To improve the appeal of documentation, the front desk leader drafted a protocol for document printing and preparation, which the team approved. To better provide services at the promised time, the team is performing a timepoint analysis of patient flow with the goal of reducing patient wait time. Use of the questionnaire will continue during and after our intervention, with comparison of pre- and postintervention data serving as a measure of the intervention's effectiveness, as well as identifying areas for continuous quality improvement.

\section{DISCUSSION}

Our results demonstrate that patient perception of quality was lowest for "The department's physical facilities are visually appealing" and "Documentation such as sign-in sheet, handouts, and brochures are visually appealing." That the patients should have a viewpoint on this issue should not come as a surprise, given that patients enter the facility (the radiology department) and receive documentation both at that time and throughout their stay there. "The department provides services at the right time" had the highest frequency of low scores $(\leq 3)$; although most people did not see timing as a significant issue, a few people were very displeased with it. 
TABLE 3

Differences in Perception of Quality and Satisfaction Based on Number of Visits, Sex, and Age

\begin{tabular}{|c|c|c|c|}
\hline Question no. & $\begin{array}{l}\text { First visit vs. } \\
\text { multiple visits }\end{array}$ & $\begin{array}{c}\text { Sex } \\
\text { (M vs. F) }\end{array}$ & $\begin{array}{l}\text { Age }(>50 y \\
\text { vs. } \leq 50 \text { y) }\end{array}$ \\
\hline 1 & 0.492 & 0.372 & 0.361 \\
\hline 2 & 0.475 & 0.072 & $0.030^{\star}$ \\
\hline 3 & 0.557 & 0.822 & 0.824 \\
\hline 4 & 0.592 & 0.519 & 0.208 \\
\hline 5 & 0.227 & 0.799 & 0.624 \\
\hline 6 & 0.293 & 0.923 & 0.318 \\
\hline 7 & 0.340 & 0.930 & 0.503 \\
\hline 8 & 0.117 & 0.979 & 0.652 \\
\hline 9 & 0.968 & 0.666 & 0.431 \\
\hline 10 & 0.937 & 0.325 & 0.888 \\
\hline 11 & 0.616 & 0.719 & 0.823 \\
\hline 12 & 0.979 & 0.452 & 0.965 \\
\hline 13 & 0.913 & 0.847 & 0.729 \\
\hline 14 & 0.523 & 0.999 & 0.423 \\
\hline 15 & 0.877 & 0.064 & 0.273 \\
\hline 16 & 0.566 & 0.607 & 0.800 \\
\hline 17 & 0.889 & 0.631 & 0.779 \\
\hline 18 & 0.838 & 0.588 & 0.593 \\
\hline 19 & 0.942 & 0.758 & 0.812 \\
\hline 20 & 0.559 & 0.687 & 0.865 \\
\hline 21 & 0.760 & 0.938 & 0.465 \\
\hline 22 & 0.881 & 0.681 & 0.884 \\
\hline 23 & 0.537 & 0.365 & 0.508 \\
\hline 24 & 0.696 & 0.852 & $0.006^{\star}$ \\
\hline 25 & 0.383 & 0.307 & 0.905 \\
\hline 26 & 0.568 & 0.056 & 0.525 \\
\hline 27 & 0.929 & 0.232 & 0.089 \\
\hline \multicolumn{4}{|c|}{$\begin{array}{l}{ }^{*} P<0.05 \text { (statistically significant). } \\
\text { Data are } P \text { values. }\end{array}$} \\
\hline
\end{tabular}

Patients reported lower satisfaction with the front desk services than with the services provided by technicians and radiologists. The level of service at the front desk is critical to the experience and perceptions of patients in a radiology department, as it is the front desk staff who are responsible for scheduling, informing, responding to needs of, and communicating with patients throughout the day. This survey response demonstrates the need to direct increased attention and resources toward optimizing structures and processes at the front desk in order to maximize quality and patient satisfaction. We also found that perceptions of the quality of care and satisfaction in it were independent of the patient's age, sex, and number of recent visits to the radiology department.

This study used a standardized survey adapted from SERVPERF to quantitatively measure patients' perceptions of quality and satisfaction at the point of care within a tertiary institution's PET center and identify areas for improvement. There have been few studies attempting this task in a diagnostic radiology center $(14,15)$ and even fewer reports of subsequent quality improvement interventions guided and measured by this information. Blomberg et al. used a modified version of the "Quality from the
Patient's Perspective" survey to identify perceptions on quality and the associated patient demographics (14). Most of the questions in the survey focused on the services the patients received before arriving at the diagnostic radiology center. Basu et al. used patient-reported data to determine patients' preferences regarding receipt of imaging results (15).

The "Hospital Consumer Assessment of Health Care Providers and Systems" survey, which has become the standard for measuring patient experience in the hospital system, is given to samples of inpatients and measures 9 key aspects of care (16), most of which are not reflective of services provided by radiology departments. In response, Press Ganey Associates, under the "Consumer Assessment of Healthcare Providers and Systems" program, developed an outpatient survey, "Outpatient and Ambulatory Surgery," more suitable for radiology departments (17). These questionnaires are not provided to patients at the time they undergo imaging and therefore likely have a limited effectiveness in capturing patients' perceptions of the service. We need a standardized way of measuring patients' perceptions at the point of care that reflects the type of service provided. Although there have been various studies of the use of SERVPERF in hospital settings $(13,18)$, we did not come across any studies of its use to assess patients' perceptions of quality in a U.S. diagnostic radiology center.

Patient-centered care has received increased focus in health care since its inclusion in the Institute of Medicine's Landmark report, Crossing the Quality Chasm, as 1 of the 6 aims of quality $(1,19)$. Patient-centered care is defined as "care that is respectful of and responsive to individual patient preferences, needs, and values" (1). This definition highlights the need for active patient engagement in the health-care design and delivery process. This approach to health care is one that radiology has been slow to incorporate, prompting the Radiological Society of North America to launch, in 2012, a campaign called, "Radiology Cares: The Art of Patient-Centered Practice." One of its goals was to encourage meaningful engagement by radiologists in their patients' experiences throughout the continuum of radiologic care $(20)$.

The use of patient-reported data ensures well-directed quality interventions through prioritization of initiatives based on the patients' greatest concerns. Prioritizing interventions based on value and utility is increasingly necessary because of the financial restraints within which health care operates. Patient-reported measures of experience have been shown to be reliable for determining the quality of a hospital's services from the patient's perspective $(16,21,22)$. This type of objective data can potentially be used to create industrywide standard metrics by which to compare performance between departments and create benchmarks, as is done with standardized surveys such as the "Hospital Consumer Assessment of Health Care Providers and Systems" (16). 
Our study had several limitations. The survey did not have open-ended questions and therefore did not allow patients to elaborate and be specific. This limitation undermined the patient centeredness of our quality improvement initiatives. Furthermore, our survey focused on the experience of only patients undergoing PET/CT examinations, not those undergoing imaging with other modalities. This limitation could lead to an inherent bias of quality with regard to one modality as opposed to others. Another limitation is that many items on our survey did not point to a specific individual or group. For example, the statement that "employees insist on error-free documentation" did not help ascertain whether the employees in question staffed the front desk, were technicians, or were physicians. Care should therefore be taken when using the tool to make managerial decisions, with any changes being applied at the system level rather than the individual level. It is also important to recognize that the survey is amenable to context-specific modifications, which are encouraged to improve its face validity.

\section{CONCLUSION}

Our study measured patient's perceptions of quality for use as evidence-based guidance of quality-improvement interventions while providing baseline data by which to measure the effects of subsequent interventions. There is a need for continuous development and use of metrics of performance at the point of care in radiology departments, with the goal of eventually creating industrywide standard metrics for comparison of performance between radiology departments and creation of benchmarks. Measurements of satisfaction and perceived quality are likely to be more accurate when performed immediately after services are provided rather than weeks later, as is the current standard.

\section{DISCLOSURE}

No potential conflict of interest relevant to this article was reported.

\section{REFERENCES}

1. Institute of Medicine. Crossing the Quality Chasm: A New Health System for the 21st Century. Washington, DC: National Academies Press; 2001:1192.

2. Varkey P, Reller MK, Resar RK. Basics of quality improvement in health care. Mayo Clin Proc. 2007;82:735-739.

3. A quick look at quality. U.S. Department of Health and Human Services website. http://archive.ahrq.gov/consumer/qnt/qntqlook.htm. Accessed October 5, 2017.

4. Reynolds A. Patient-centered care. Radiol Technol. 2009;81:133-147.

5. Davis K, Schoenbaum SC, Audet AA. 2020 vision of patient-centered primary care. J Gen Intern Med. 2005;20:953-957.

6. Harvard Business Review on Knowledge Management. Boston, MA: Harvard Business Press; 1998.

7. Hughes RG. Tools and strategies for quality improvement and patient safety. In: Hughes RG, ed. Patient Safety and Quality: An Evidence-Based Handbook for Nurses. Rockville, MD: Agency for Healthcare Research and Quality; 2008:3-1-3-39.

8. Cleary PD. The increasing importance of patient surveys: now that sound methods exist, patient surveys can facilitate improvement. BMJ. 1999;319:720-721.

9. Cronin JJ Jr, Taylor SA. Measuring service quality: a reexamination and extension. J Mark. 1992;56:55-68.

10. Bayraktaroglu G, Atrek B. Testing the superiority and dimensionality of SERVQUAL vs. SERVPERF in higher education. Qual Manag J. 2010;17:47-59.

11. Rodrigues LL, Barkur G, Varambally K, Golrooy Motlagh F. Comparison of SERVQUAL and SERVPERF metrics: an empirical study. TQM J. 2011;23:629-643.

12. Llosa S, Orsingher C, Carrillat FA, Jaramillo F, Mulki JP. The validity of the SERVQUAL and SERVPERF scales: a meta-analytic view of 17 years of research across five continents. Int J Serv Ind Manage. 2007;18:472-490.

13. Taylor SA, Cronin JJ Jr. An empirical assessment of the SERVPERF scale. J Mark Theory Pract. 1994;2:52-69.

14. Blomberg F, Brulin C, Andertun R, Rydh A. Patients' perception of quality of care in a radiology department: a medical-physical approach. J Radiol Nurs. 2010;29:10-17.

15. Basu PA, Ruiz-Wibbelsmann JA, Spielman SB, et al. Creating a patient-centered imaging service: determining what patients want. AJR. 2011;196:605-610.

16. Isaac T, Zaslavsky AM, Cleary PD, Landon BE. The relationship between patients' perception of care and measures of hospital quality and safety. Health Serv Res. 2010;45:1024-1040.

17. Lang EV, Yuh WT, Ajam A, et al. Understanding patient satisfaction ratings for radiology services. AJR. 2013;201:1190-1195.

18. Gómez-Besteiro MI, Somoza-Digon J, Einoder-Moreno M, Jimenez-Fraga MN, Castineira-Pereira S, Feijoo-Fuentes ML. Health care quality perceived by the patients in an urban health centre in A Coruña. Enferm Clin. 2012;22:182-190.

19. Barry MJ, Edgman-Levitan S. Shared decision making: the pinnacle of patientcentered care. N Engl J Med. 2012;366:780-781.

20. Radiology cares. https://www.rsna.org/Radiology-Cares/. Accessed October 5, 2017.

21. Boulding W, Glickman SW, Manary MP, Schulman KA, Staelin R. Relationship between patient satisfaction with inpatient care and hospital readmission within 30 days. Am J Manag Care. 2011;17:41-48.

22. Doyle C, Lennox L, Bell D. A systematic review of evidence on the links between patient experience and clinical safety and effectiveness. BMJ Open. 2013;3:e01570. 